\title{
Method of smoothing the surface of additively manufactured polylactide by thermal treatment in sodium chloride
}

\author{
Jan Pawlik ${ }^{1, *}$, Damian Dzienniak ${ }^{1}$ \\ ${ }^{1}$ Department of Manufacturing Systems, Faculty of Mechanical Engineering and Robotics, \\ AGH University of Science and Technology, Kraków, Poland
}

\begin{abstract}
The paper contains a study of the influence of thermal treatment of the 3D-printed polylactide parts in sodium chloride dust on the surface roughness of the manufactured part. The conducted experiment features annealing with the use of two different sizes of $\mathrm{NaCl}$ crystals and two levels of temperature. All the samples were made with natural polylactic acid filament using the fused deposition modeling (FDM) method. The samples were put into a salt scaffold and placed in the electric furnace to remelt the surface of the part while keeping pressure on the walls to prevent unwanted deformation. The results show that it is possible to improve the quality of additively manufactured component's surfaces as long as optimal parameters are applied.
\end{abstract}

\section{Introduction}

Additive Manufacturing (AM) technology's popularity and progress have skyrocketed throughout the last decade and it tends to create new fields of possible improvement. One major issue, regarding the functionality of manufactured parts, is their surface roughness. As long as one realizes his $3 \mathrm{D}$ printing needs with the use of the light-curing resin-based or powder sintering solutions, roughness-related problems do not concern this person that much. On the contrary, users of the most popular and most available method, which is Fused Deposition Modeling (or FDM), are familiar with the characteristic layer lines.

The relatively high level of roughness of FDM-printed parts can cause several negative effects - for instance, two working and coupled 3D-printed elements may be prone to excessive wear [1]. The visible lines can provide a negative or unprofessional aesthetic impression - either if the part is a mere prototype, waiting for the investor evaluation, or if the part is used as a master model for casting. Dimensional inaccuracy is a separate, yet important issue.

The roughness of 3D-printed components is a byproduct of the manufacturing technology itself. The principle of operation of the FDM process is the following:

* Corresponding author: jan.pawlik@agh.edu.pl 
- The material in the form of the filament of a round cross-section is loaded from the spool to the hot-end.

- The hot-end contains heating block and nozzle of user-chosen diameter

- The material is melted and extruder through the nozzle onto the surface of the printer's bed or previous layer.

- As the filament exits the nozzle it exists in a form of a round cylinder and is fused in the form of a flattened cylinder.

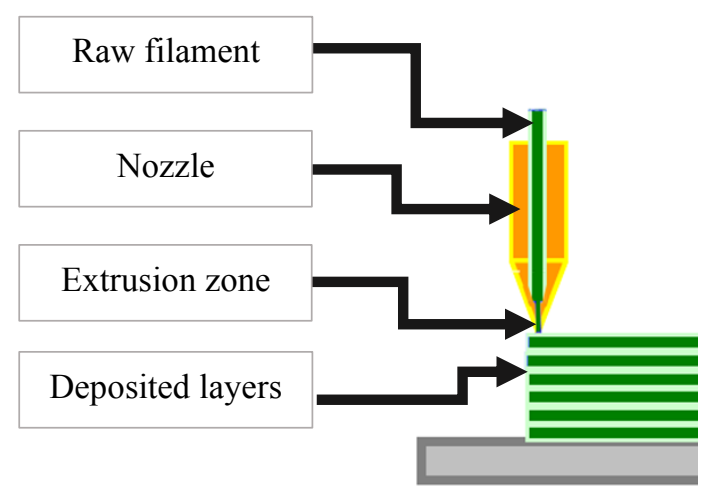

Fig. 1. A schematic diagram of the cause of surface irregularity in the Fused Deposition Modeling method of additive manufacturing.

The resulting roughness of the parts is a product of a type of numerous coefficients, such as material, nozzle diameter, layer height, and temperature [2], besides the general stiffness and condition of the printing machine. Yet despite the excellent shape of the hypothetical 3D-printer and fine-tuning of the parameters, the technology itself limits the user to a certain level of achievable smoothness of the manufactured object [3] and lower levels of roughness can hitherto be achieved only by the application of a post-processing technique.
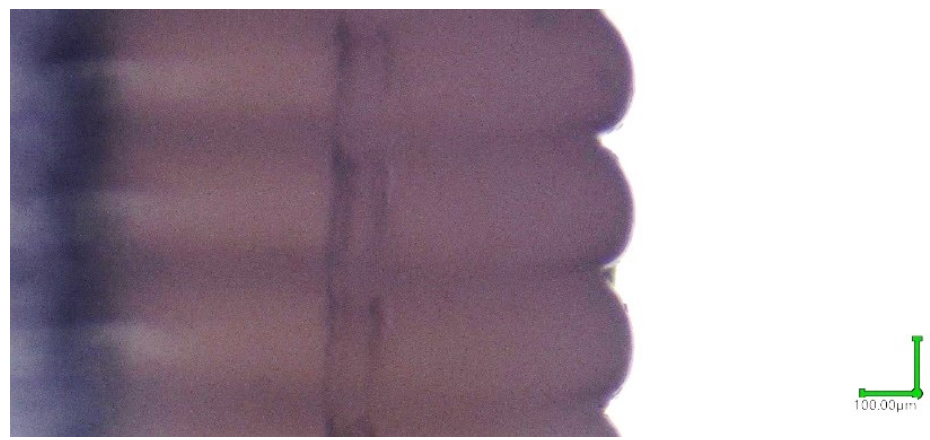

Fig. 2. Microscopic image of the edge of FDM-printed object which shows the origin of the surface irregularity. Magnification 30x.

There are many methods to address the problem of surface roughness; yet the post-processing techniques may be classified into three main categories: mechanical, chemical, and thermal approaches. 


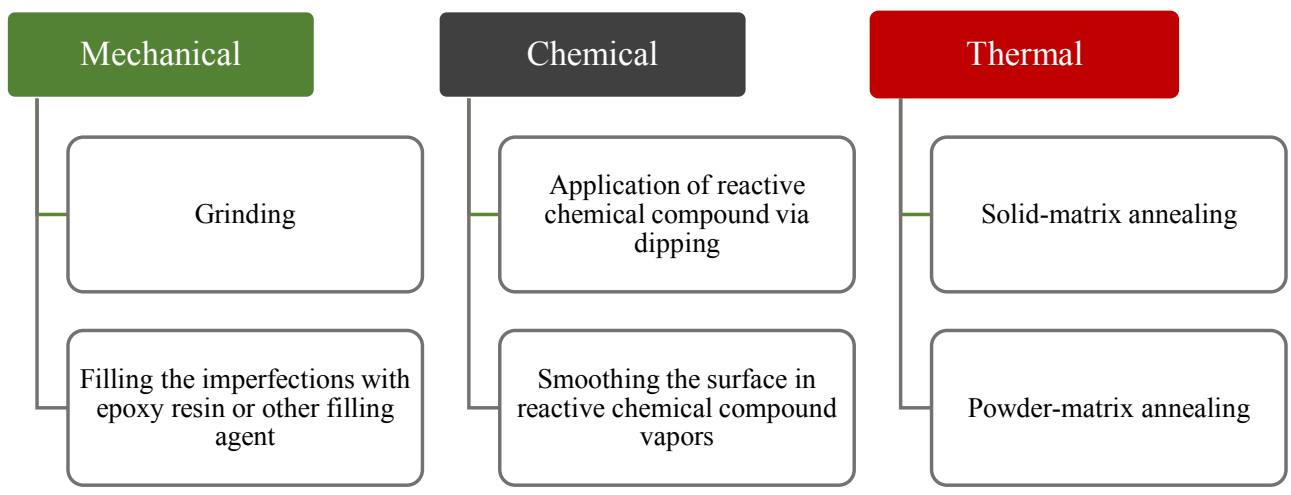

Fig. 3. A schematic diagram of the methods of smoothing the surface of 3D-printed parts

Certain 3D-printing filament materials, such as ABS could be treated with acetone vapors to reduce the roughness parameters [4]. However, that process is difficult to control, especially in thin-walled objects and it cannot be applied to treat polylactide (PLA), as this material requires more advanced chemical compounds [5]. As the PLA is not only the most popular material for filament, it is considered as being the easiest to print and has the least impact on the environment [6], being a bio-degradable material [7].

The authors decided to test the impact of salt-matrix PLA annealing on the surface roughness of the additively manufactured parts.

\section{Method of investigation}

\subsection{Preparation of samples}

The authors used a version of a desktop 3D-printer, based on the solutions provided by the RepRap community. The test samples were printed in a form of a thin-walled cube with the nominal dimension of $30 \times 30 \times 30 \mathrm{~mm}$. There were decided to use the filament containing polylactic acid with as little admixtures as possible in order not to interfere with the experiment results with extra coefficients (such as modification of the surface profile with particles of e.g. glitter), although the authors are aware of the fact, that the manufacturers may add some sort of addition, which may be a trade secret (e.g. flux agent). The spool of "PLA Natural" filament from Rosa 3D Filaments were used, and the technical datasheet of the product is available below:

Table 1. Technical datasheet of polylactic acid filament, PLA Natural from Rosa 3D Filaments.

\begin{tabular}{|c|c|}
\hline Polylactic acid filament data & Value \\
\hline Diameter & $1,75 \mathrm{~mm}$ \\
\hline Density & $1,24 \mathrm{~g} / \mathrm{cm} 3$ \\
\hline Smell & None \\
\hline
\end{tabular}




\begin{tabular}{|c|c|}
\hline Strain at yield & $6 \%$ ASTM D882 \\
\hline Ultimate tensile strength & 53 MPa ASTM D882 \\
\hline Tensile modulus & 3500 MPa ASTM D882 \\
\hline Glass transition temperature & $55^{\circ} \mathrm{C}$ ASTM E2092 \\
\hline
\end{tabular}

There were decided to manufacture parts with the use of the nozzle of $0.5 \mathrm{~mm}$ in diameter and $0.25 \mathrm{~mm}$ layer height.

Table 2. Printing parameters of the test samples.

\begin{tabular}{|c|c|}
\hline Parameter & Value \\
\hline Extrusion width & $0.5 \mathrm{~mm}$ \\
\hline Layer Thickness & $0.25 \mathrm{~mm}$ \\
\hline Number of bottom layers & $4=1 \mathrm{~mm}$ \\
\hline Number of perimeters & $2=1 \mathrm{~mm}$ \\
\hline Infill & $0 \%$ \\
\hline Average Nozzle Temperature & $215^{\circ} \mathrm{C}$ \\
\hline Bed Temperature & $60^{\circ} \mathrm{C}$ \\
\hline
\end{tabular}

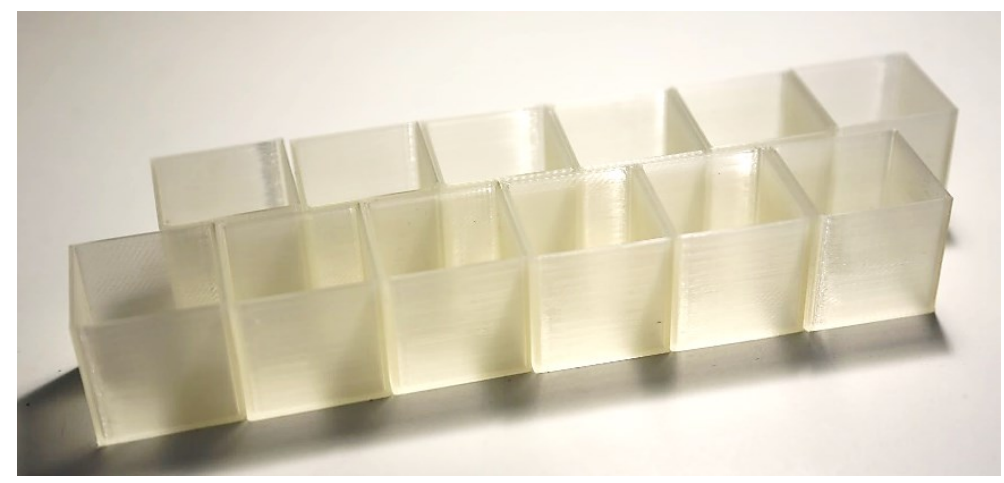

Fig. 4. Image of raw, untreated 30x30x30mm cubes made out of PLA with $1 \mathrm{~mm}$ wall thickness.

\subsection{Sodium chloride dust}

In this study was used the dust of regular $\mathrm{NaCl}$ halite crystals. The choice is to come from the fact, that even if the thermoplastic material melts on the surface and bonds with the crystal, the sodium chloride can be easily removed by dissolving in water.

The sodium chloride powder was prepared as two separate ranges of gradation. The first range being non-processed salt of the rather spread size of grains. The second one being salt processed in a hammer mill to achieve very small grains, with close size. The graphical comparison between those 
two levels is given in the picture below. The size ranges were roughly assumed to be $200-600 \mu \mathrm{m}$ for the first range of gradation and 10-100 $\mu \mathrm{m}$ for the second range of gradation..
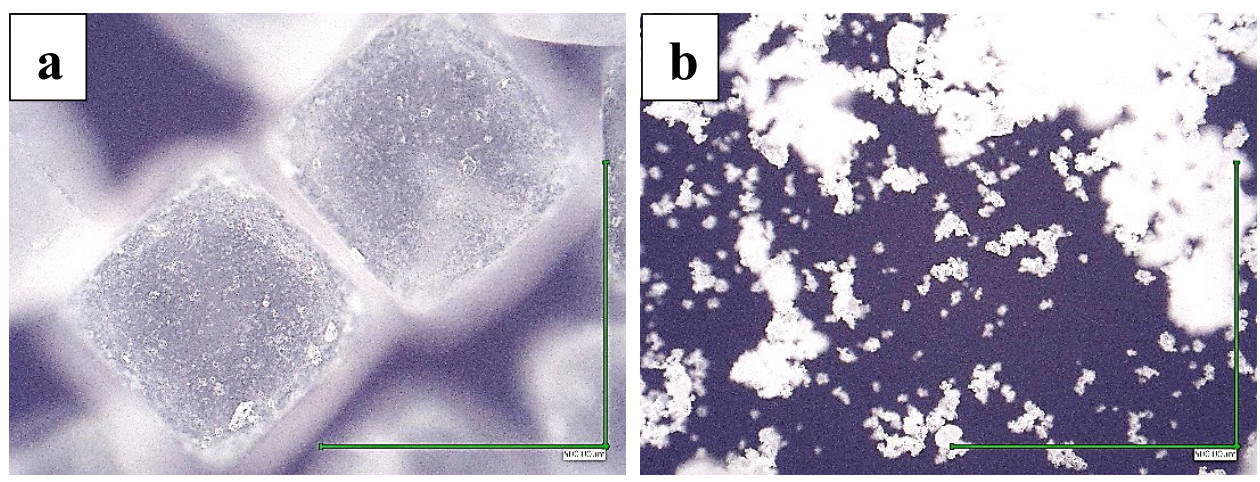

Fig. 5. Microscopic image of the halite crystal grain sizes. On the left (a) are the non-processed salt crystal grains. On the right (b), there are salt crystals after treatment in the hammer mill. The XY scale bar in both cases is $500 \mu \mathrm{m}$.

Investigation of two ranges of grain size helped to determine how the salt matrix annealing can improve the surface quality. There were obtained quantitative information on how does the salt crystal grain size affects the final roughness of the printed element.

\subsection{Annealing stand setup}

The annealing process required a defined stand setup and procedure to supply reliable data. The additively manufactured part was placed into a container, filled with soft salt powder dose. Afterward, the powder was pressurized to remove most of the air particles stuck between grains. Omitting the pressurizing step leads to poor results. The part had some degrees of freedom in salt powder, and the annealing process caused shape deviations.

The container with the annealed part, surrounded by well-tamped salt powder, was equipped with a thermocouple to provide the temperature feedback. Existed the awareness, that the thermocouple could be offset from the outer edge of the annealed part. Therefore the reading was slightly higher than the actual temperature of the close surrounding of the $3 \mathrm{D}$ printed cube. In future studies, that uncertainty will be avoided.

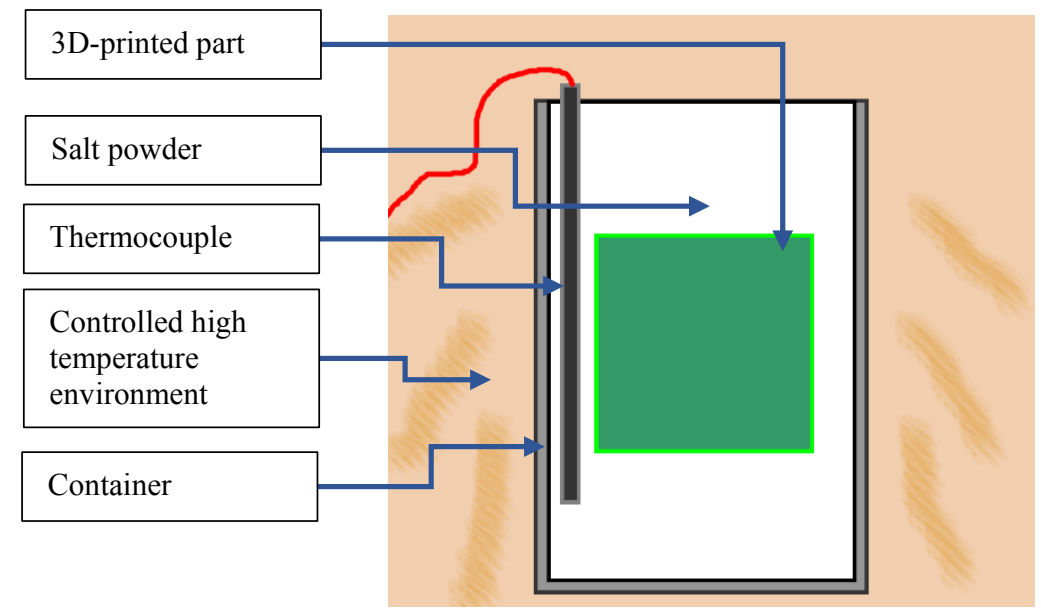


Fig. 6. Scheme of a setup applied for the annealing process

\subsection{Annealing process}

The container with the part in salt was inserted into the electric furnace. There were chosen 2 levels of temperature: $125^{\circ} \mathrm{C}$ and $175^{\circ} \mathrm{C}$. There was also an attempt to anneal PLA in the temperature exceeding the melting point of PLA, namely $225^{\circ} \mathrm{C}$. The result however gave a clear sign, that it is over the possible range - the geometry was utterly damaged. The structure of the material became significantly porous and very brittle and the cube had a colour change.

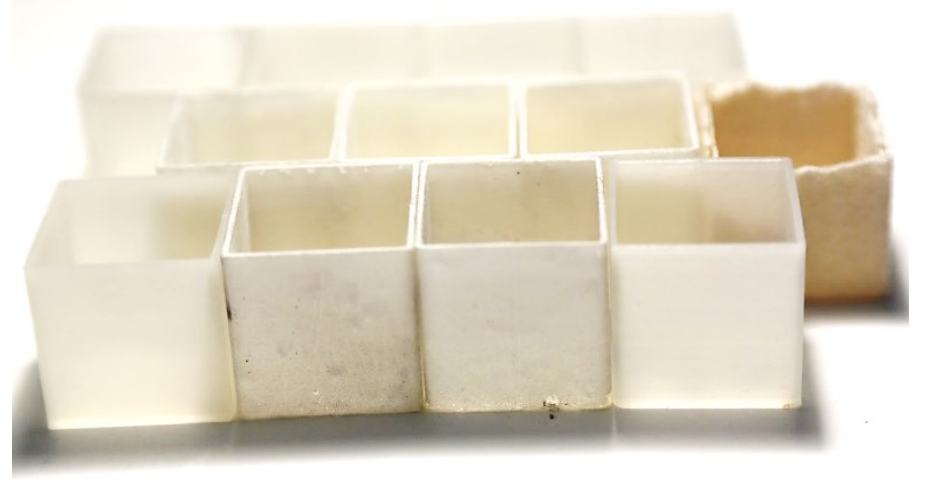

Fig. 7. Parts annealed with different parameters of the process. In the second row on the right side, it can be seen the overheated and damaged sample.

After reaching the target temperature, the samples were left in the furnace for 30 minutes for the annealing process to take place. Afterward, they were taken out to cool down and solidify. The succeeding step was to gently take the plastic part out of the salty scaffold and rinse them thoroughly with water to remove sodium chloride residues.

Table 3. Information about of batch type for the scrutinized phenomenon

\begin{tabular}{|c|c|c|c|}
\hline $\begin{array}{c}\text { Sample batch } \\
\text { description }\end{array}$ & $\begin{array}{c}\text { Type of salt } \\
\text { grain }\end{array}$ & $\begin{array}{c}\text { Temperature } \\
\text { of the process }\end{array}$ & $\begin{array}{c}\text { Number } \\
\text { of samples }\end{array}$ \\
\hline 1. CSLT & $200-600 \mu \mathrm{m}$ & $125^{\circ} \mathrm{C}$ & 3 \\
\hline 2. CSHT & $200-600 \mu \mathrm{m}$ & $175^{\circ} \mathrm{C}$ & 3 \\
\hline 3. FSLT & $10-100 \mu \mathrm{m}$ & $125^{\circ} \mathrm{C}$ & 3 \\
\hline 4. FSHT & $10-100 \mu \mathrm{m}$ & $175^{\circ} \mathrm{C}$ & 3 \\
\hline 5. CS225 & $200-600 \mu \mathrm{m}$ & $225^{\circ} \mathrm{C}$ & 1 \\
\hline
\end{tabular}

For every batch, there were prepared 3 test cubes. The fifth test cube was a singular try. Four cubes were necessary to obtain valid and reliable measurement results - every cube had 4 walls, hence there was possible to run 16 different roughness measurements. 


\subsection{Measured surface roughness coefficients}

The two roughness parameters were used to estimate the possibilities of the annealing in the salt powder method, namely $R_{a}$ and $R_{z}$.

The $R_{a}$ parameter (Eq. 1) stands for arithmetic mean deviation of the height of the roughness profile related to the center line. Theoretically, an integral of a continuous "roughness signal" should be calculated. However as the measuring device had digital data output, the parameter could be approximated by the sum of the sampled height distances.

$$
R_{a}=\frac{1}{l} \int_{0}^{l}|z(x)| d x \approx \frac{1}{n} \sum_{i=1}^{n}\left|z_{i}\right|
$$

The other parameter $-R_{z}$ - represents the sum of two mean values. One being the average of five longest positive distances (called "peaks", denoted as $z_{p i}$ ) from the center line. The second being five longest negative (called "valleys", denoted as $z_{v i}$ ) distances from the mentioned line, as is stated in Eq.2. All of the 10 characteristic points lay within the evaluation length.

$$
R_{z}=\frac{1}{5}\left(\sum_{i=1}^{5}\left|z_{p i}\right|+\sum_{i=1}^{5}\left|z_{v i}\right|\right)
$$

Those two parameters were designated to be sufficient for determining, whether of the annealing in the salt powder method affects the outer surface quality.

\section{Measurements}

The measurements of the roughness profile were done with the use of contact surface and contour measuring instrument - Formtracer SV-C4500 (Mitutoyo), equipped with SV-C3000 roughness detector. Additionally, microscopic visual inspection during the measurements was conducted. There are some other methods for evaluating the roughness of additively manufactured parts described in $[8,9]$, but for the sake of this study, it was decided to measure just the profile which is perpendicular to the layer orientation.

The distance of the measured roughness profile was $4.8 \mathrm{~mm}$ long, whereas both ends of the profile were cut off to make the process more reliable, leaving $4 \mathrm{~mm}$ of profile took into account. The discreet sampling was set to $0.0005 \mathrm{~mm}$. The end parameters were calculated by the Formtracer proprietary DAQ software, called Formtracepak, yet the authors additionally exported some text dat files, containing the respective roughness profiles, to compare them visually in Matlab environment.

As every sample had 4 walls, the 12 measurements of each group was taken (CSLT, CSHT, etc.) to exclude any local irregularities. 


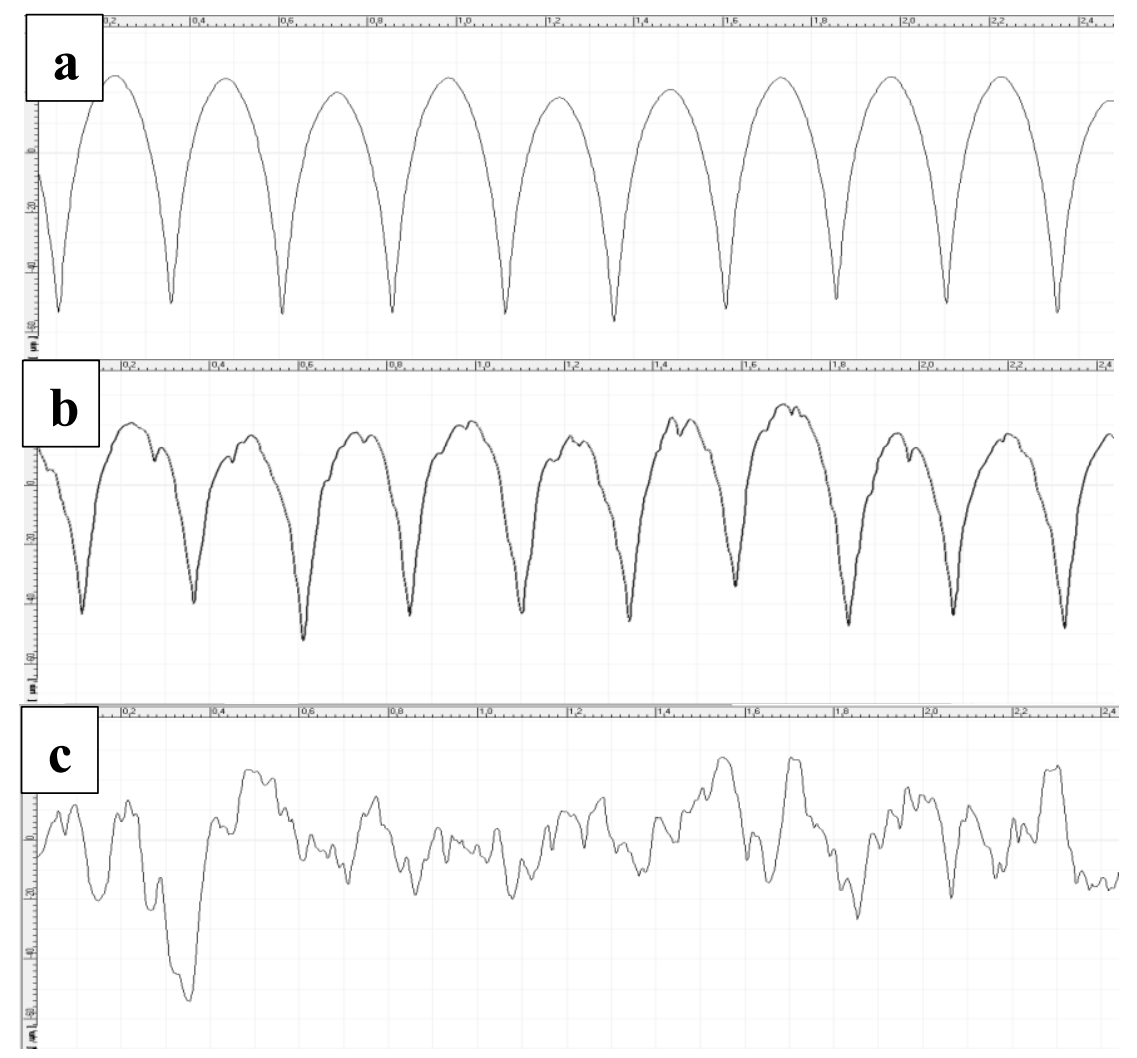

Fig. 8. Roughness profiles obtained from the Formtracepak software. The profile "a" represents the surface of the raw, untreated specimen. Profiles " $b$ " and "c" correspond to coarse and fine salt annealing accordingly.
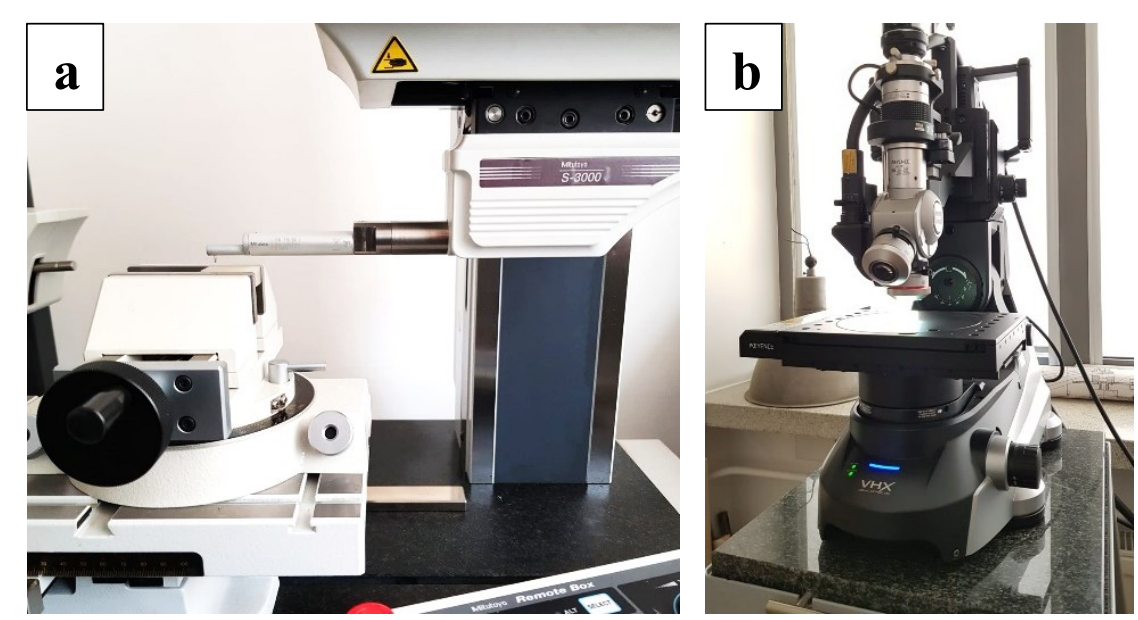

Fig. 9. The roughness measuring instruments facilitated in the current study. On the left (a) there is the contact surface and contour measuring instrument - Formtracer SV-C4500, on the right (b) there is Keyence VHX-7000 microscope used to acquire high-resolution pictures appearing in this paper. 


\section{Results}

The results of the microscopic visual inspection indicate, that the overall surface quality was indeed improved. The bumps, visible on the raw specimen were nearly completely eliminated, leaving a layer-less impression. All distances of the peaks and the valleys from the center line were reduced..
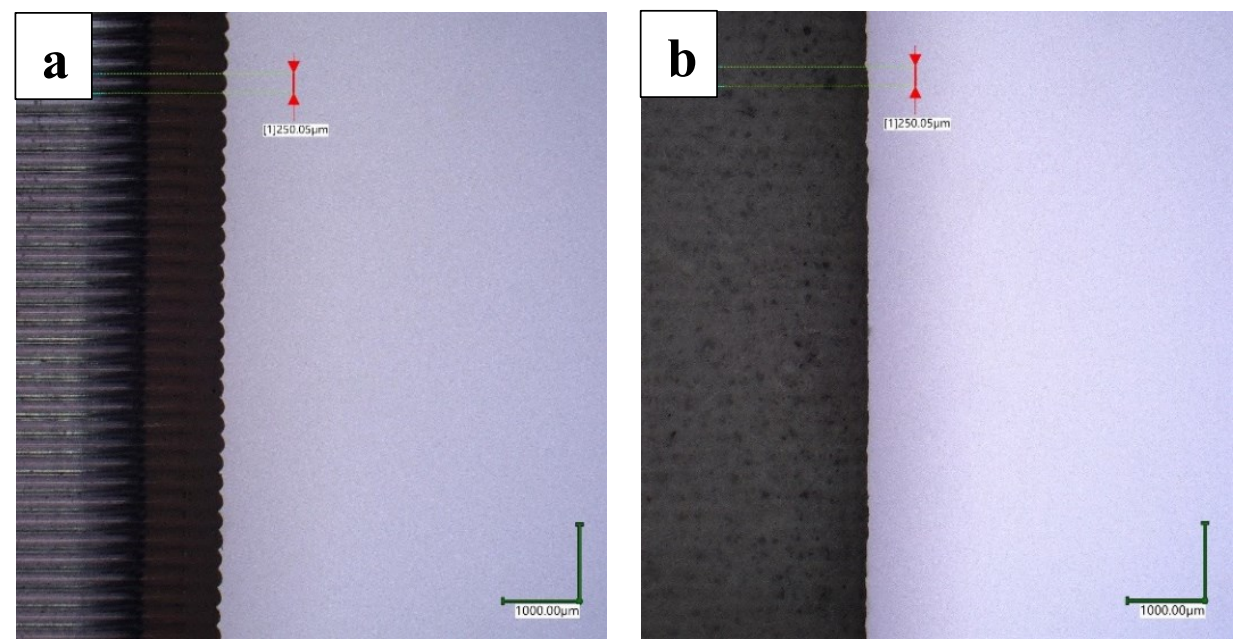

Fig. 10. The raw specimen (on the left, denoted with "a") versus the post-processed specimen (on the right, denoted with "b")

The .dat files, obtained from the contact roughness measuring tool were imported to Matlab environment as a discreet signal and as such, they were normalized and averaged. The results of the described operations are given below in the tabular and graphical form.

Table 4. Quantified roughness value after particular forms of treatment:

\begin{tabular}{|c|c|c|}
\hline Type of annealing & Average $\mathbf{R}_{\mathbf{a}}$ & ${\text { Average } \mathbf{R}_{\mathbf{z}}}$ \\
\hline None & $18 \mu \mathrm{m}$ & $82 \mu \mathrm{m}$ \\
\hline Coarse salt, $125^{\circ} \mathrm{C}$ & $17 \mu \mathrm{m}$ & $77 \mu \mathrm{m}$ \\
\hline Coarse salt, $175^{\circ} \mathrm{C}$ & $36 \mu \mathrm{m}$ & $180 \mu \mathrm{m}$ \\
\hline Fine salt, $125^{\circ} \mathrm{C}$ & $14 \mu \mathrm{m}$ & $79 \mu \mathrm{m}$ \\
\hline Fine salt, $\mathbf{1 7 5}^{\circ} \mathbf{C}$ & $\mathbf{1 0} \boldsymbol{\mu m}$ & $\mathbf{8 1} \boldsymbol{\mu m}$ \\
\hline Coarse salt, $220^{\circ} \mathrm{C}$ & $64 \mu \mathrm{m}$ & $342 \mu \mathrm{m}$ \\
\hline
\end{tabular}




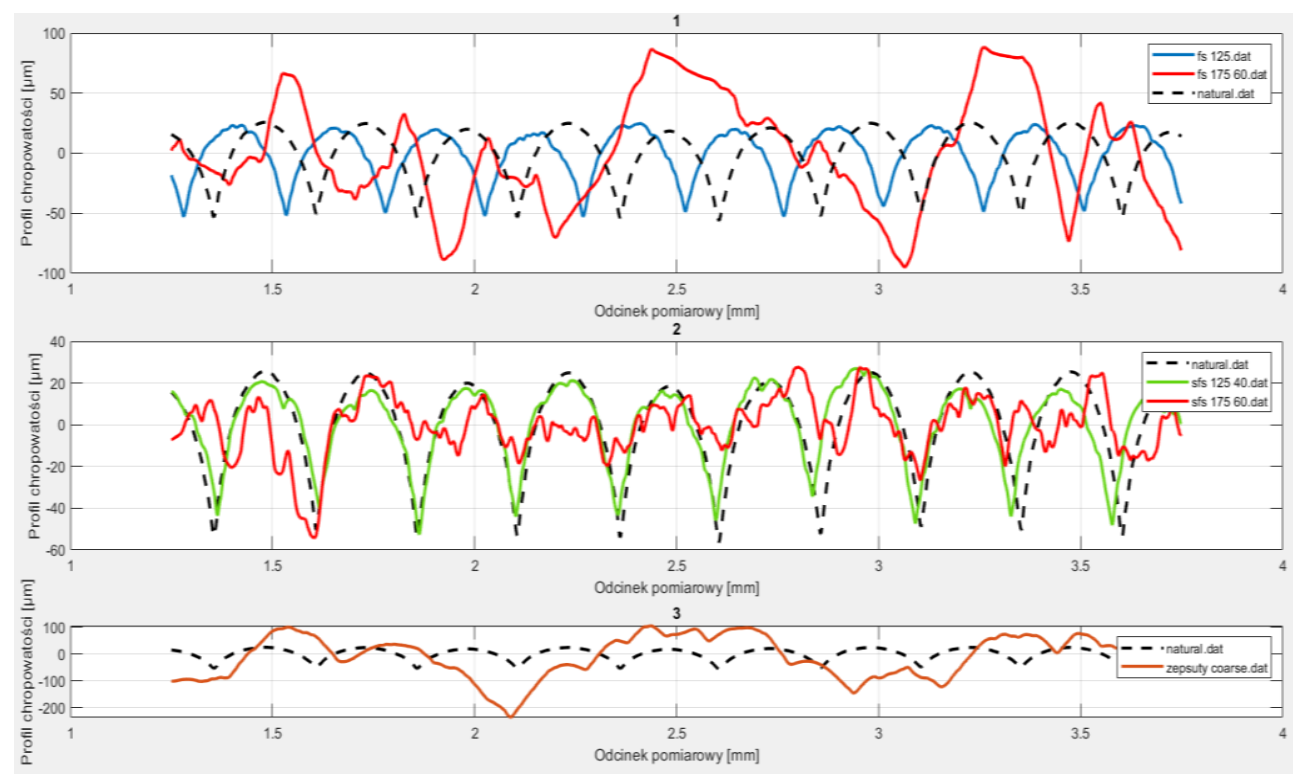

Fig. 11. The comparison between measured surface quality. The dashed line represents the raw, untreated surface and is repeated in every graph for reference.

\section{Discussion and Conclusions}

The measurements have shown, that surface quality can be improved with the use of annealing in the salt powder method. Whilst the roughness of the exterior shell with an uncomplicated geometry could be achieved with mechanical post-processing with even better results, the method used and described in this paper is eligible to use when the surface of the inner geometry needs refinement or when the dimensional accuracy is important.

The process requires further development in the domain of process parameters. The thermocouple, used in the annealing setup was a bit off-set from the external walls of the processed part, thus the temperature readings might be inaccurate. Additionally, the temperature ranges may be fine-tuned - this paper concerns the study of two distant levels of temperature, which provide plausible results. The singular try with the temperature level considerably exceeding the melting point of the thermoplastic (here: $225^{\circ} \mathrm{C}$ ) shows that both the surface and the general geometry and other mechanical properties are significantly damaged.

The main disadvantage of the annealing in the salt powder method is the tendency of sodium chloride to agglomerate in bigger clusters of micro-crystals, especially under additional pressure. This tendency may force the user to re-grind the sodium chloride crystals with every round of annealing. It was decided to look for another fine-grained and reasonably priced material for annealing in the future study.

A side effect of the salt powder method was that the treated objects become water-tight under atmospheric pressure due to enhancing the inter-layer adhesion. Normally, the additively manufactured parts with thin walls do not provide the satisfactory level of tightness. 


\section{References}

1. Szmidt, A., \& Rębosz-Kurdek, A. (2017) Mechanik, 3(0), 258-261.

2. Carpino, F., Moore, L. R., Zhang, Y., Li, N., \& Dai, J. (2016). The impact of temperature changing on surface roughness of FFF process.

3. Nieciąg, H., Kudelski, R., Dudek, P., \& Cieślik, J. (2020) Acta Mechanica et Automatica, 14(1), 59-68.

4. Lalehpour, A., Janeteas, C., \& Barari, A. (2018). Surface roughness of FDM parts after post-processing with acetone vapor bath smoothing process, 1505-1520.

5. Valerga, A. P., Batista, M., Fernandez-vidal, S. R., \& Gamez, A. J. (2019). Impact of Chemical Post-Processing in Fused Deposition Modelling (FDM) on Polylactic Acid (PLA) Surface Quality and Structure

6. Nagarajan, V., Mohanty, A. K., \& Misra, M. (2016) ACS Sustainable Chemistry and Engineering, 4(6), 2899-2916.

7. Richardson, B. (2012) Environment and Planning C: Government and Policy, 30(2), 282-296.

8. Buj-Corral, I., Domínguez-Fernández, A., \& Durán-Llucià, R. (2019) Materials, 12(23).

9. Alsoufi, M. S., \& Elsayed, A. E. (2017) American Journal of Mechanical Engineering, 5(5), 211-222. 